\title{
The effect of bent-up tab shear transfer enhancement shapes, angles and sizes in precast cold-formed steel-concrete composite beams
}

\author{
M. J. Irwan ${ }^{1}$, A. H. Hanizah ${ }^{2}$, I. Azmi ${ }^{2}$, P. Bambang ${ }^{1}$, H. B. Koh ${ }^{1}$ \\ \& M. G. Aruan ${ }^{2}$ \\ ${ }^{1}$ Faculty of Civil and Environmental Engineering, UTHM, \\ Batu Pahat, Johor, Malaysia \\ ${ }^{2}$ Faculty of Civil Engineering, Universiti Teknologi MARA, \\ Shah Alam, Selangor, Malaysia
}

\begin{abstract}
This paper deals with the evaluation of the effect of shapes, angles and sizes of bent-up tab shear transfer enhancement in precast cold-formed steel-concrete composite beams. The study is performed through push-out testing on 14 specimens. The push-out test has been employed to assess the shear strength as well as the behaviour of the shear transfer enhancement. It is shown that specimens employed with shear transfer enhancements increase the shear capacities of the specimens as compared to those relying only on a natural bond between cold-formed steel and concrete. In the shear transfer enhancements investigated, a new proposed shear transfer enhancement called bent-up triangular tab shear transfer (BTTST) provided the best performance in terms of strength. Shear capacities of the shear transfer enhancement also increase when the angles and sizes of bent-up tabs shear transfer enhancement is increased. It is concluded that more efficient and feasible precast cold-formed steel-concrete composite beams can be obtained with this innovator proposed shear transfer enhancement.
\end{abstract}

Keywords: cold-formed steel, composite beams, precast beams, shear transfer mechanisms. 


\section{Introduction}

The application of cold-formed steel composite concrete floor systems in small commercial and residential construction has gained popularity in recent years. The application of this system only uses cold-formed steel sheets. However, the use of cold-formed steel sections, such as C-section, as the composite floor joint in slab systems is still limited. The structural performance of cold-formed steel can be improved by using it in conjunction with other materials, such as concrete, to form the composite system. Common ways to do this are to use the cold-formed sections as composite beams in concrete slab systems [1]. However, a previous study showed that there is very little work and a lack of technical literature, such as codes of practice, regarding cold-formed steel-concrete composite beams [2]. The main problem for cold-formed steel-concrete composite beams is the welding of shear studs, due to the light gage and thickness of the sections for cold-formed steel being too small. From this viewpoint, this research is being carried out to study the possibility and performance of the use of back-to-back cold-formed steel lipped channels by bolted connection to form the I-beam. The top flange of the I-beam was modified by providing the new proposed shear transfer enhancement, named bent-up triangular tabs shear transfer (BTTST) to be used in the composite concrete floor systems. The purpose of this research was to investigate experimentally the efficiency of the BTTST in push-out testing and to determine the strength and behaviour of the shear transfer enhancement. Fourteen push-out specimens were constructed and tested to assist with evaluation.

\section{Parametric study}

Three parameters were identified as being of particular importance, as they affect the strength capacity of the shear transfer enhancement. These parameters are as follows.

\subsection{Shapes of shear transfer enhancement}

Two shapes of shear transfer enhancement were tested.

(i) Lakkavalli and Liu bent-up (LYLB) as shown in Figure 1 [3].

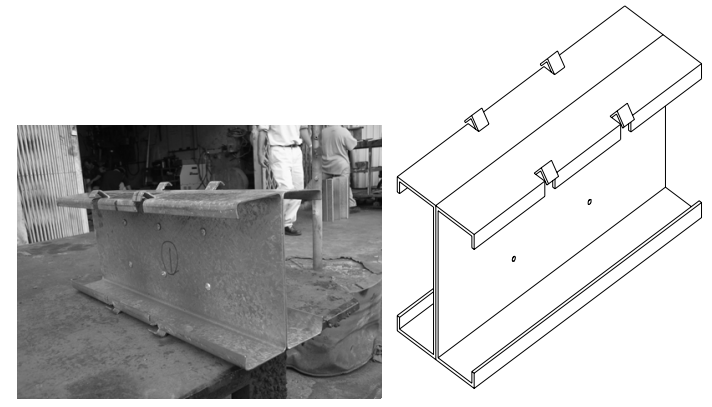

Figure 1: $\quad$ Lakkavalli and Liu bent-up tabs shear transfer (LYLB). 
(ii) A newly proposed shape, named the bent-up triangular tab shear transfer (BTTST) as shown in Figure 2.

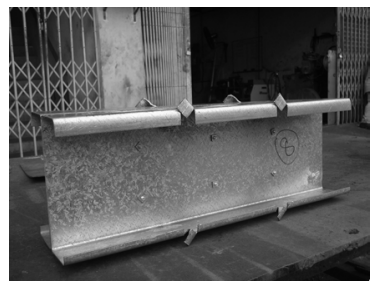

Figure 2: $\quad$ Bent-up triangular tab shear transfer (BTTST).

\subsection{Angles of shear transfer enhancement}

Three different angles $\theta$ were studied (Figure 3), i.e. $30^{\circ}, 45^{\circ}$ and $60^{\circ}$.

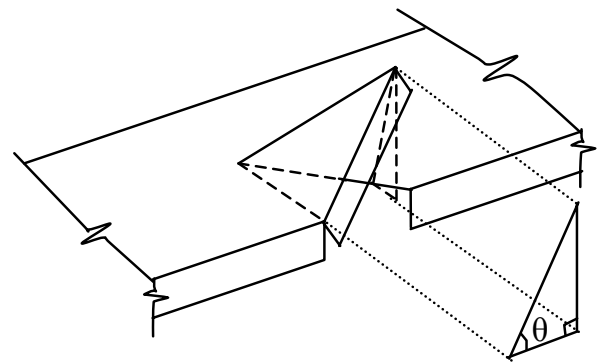

Figure 3: $\quad$ Angles, $\theta$ of the shear transfer enhancement.

\subsection{Sizes of shear transfer enhancement}

The dimensions of the tabs, (A x B) (Figure 4) are $20 \mathrm{~mm} \times 20 \mathrm{~mm}, 25 \mathrm{~mm} \times$ $25 \mathrm{~mm}$ and $30 \mathrm{~mm} \times 30 \mathrm{~mm}$.

\section{Experimental program}

\subsection{Specimen}

In this study, 14 push-out test specimens were tested to failure. Figure 5 shows the detail of the cross section of the push-out test specimen. A cold-formed steel Isection beam formed by a back-to-back lipped channel was used with the flanges cast into a $300 \mathrm{~mm}$ wide $\times 10 \mathrm{~mm}$ depth $\mathrm{x} 550 \mathrm{~mm}$ height concrete slab. One layer of $100 \mathrm{~mm}$ square welded wire fabric steel reinforcements with a diameter of 8 $\mathrm{mm}$ was provided in the concrete slab. A recess of $50 \mathrm{~mm}$ in height was provided 


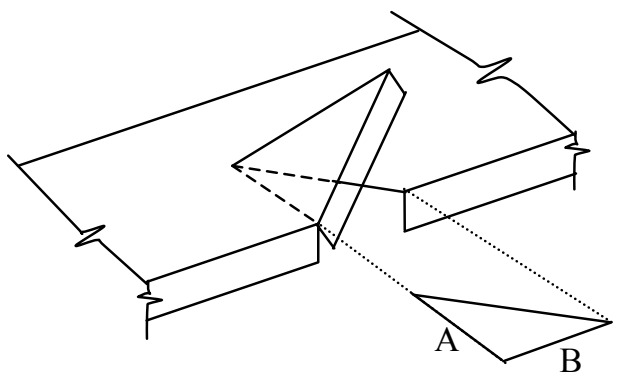

Figure 4: $\quad$ Calculated area $(\mathrm{A} \times \mathrm{B})$ of the shear transfer enhancement.
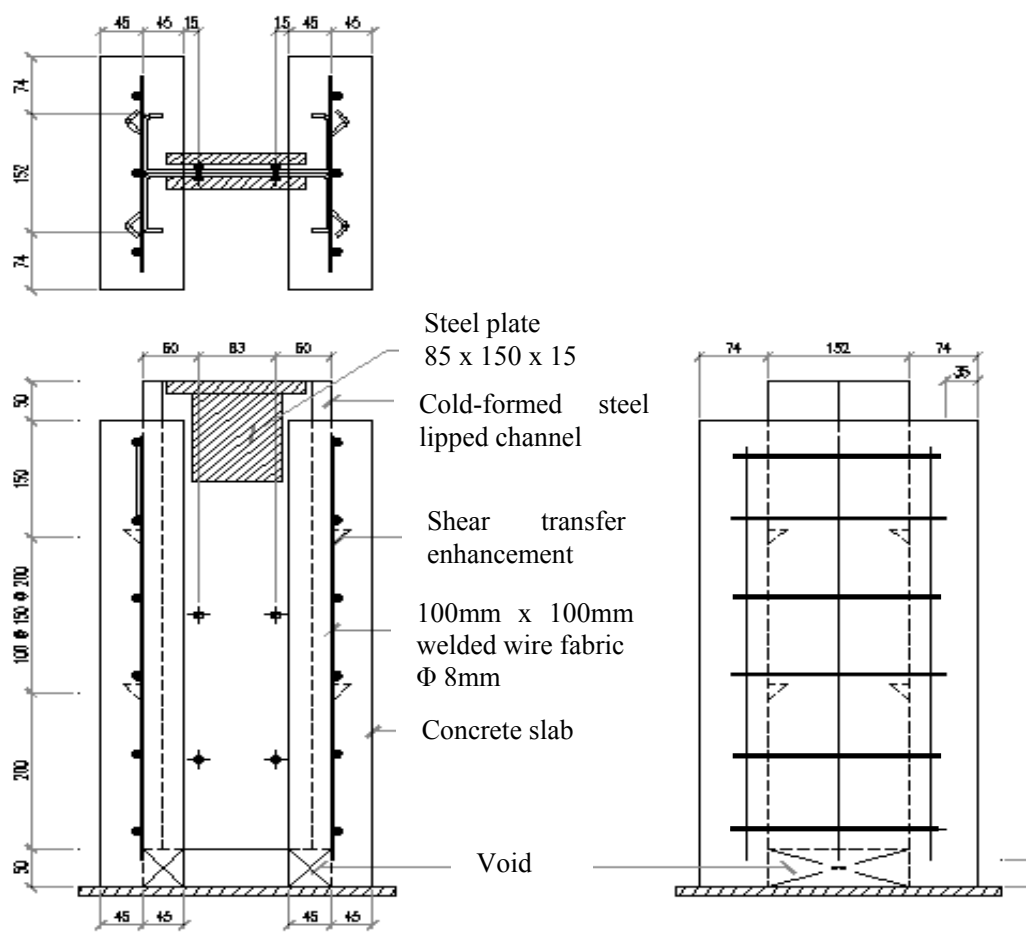

Figure 5: $\quad$ Layout for the push-out test specimen.

between the bottom of the concrete slab and the lower end of the cold-formed steel section to allow for slip during testing. Twelve specimens were provided with the shear transfer enhancement connectors in the spacing of $150 \mathrm{~mm}$ on the steel flange as shown in the figure. Meanwhile, two out of the fourteen specimens (S1 and S10) without the shear connector are used as the control 
specimens. Both sides of the flange of the I-beam for each specimen were embedded in the concrete slab to form the composite system. The details of each specimen are summarized in Table 1.

Table 1: $\quad$ Specimen push-out test.

\begin{tabular}{|c|c|c|c|c|c|}
\hline No & $\begin{array}{c}\text { Shape of } \\
\text { Enhancement }\end{array}$ & $\begin{array}{c}\text { Dimension } \\
\text { of } \\
\text { Enhancement } \\
(\mathrm{mm} \times \mathrm{mm})\end{array}$ & $\begin{array}{c}\text { Angle } \\
\text { of } \\
\text { Enhancement } \\
\text { (degree) }\end{array}$ & $\begin{array}{c}\text { Channel } \\
\text { Section } \\
\text { Thickness } \\
\text { (mm) }\end{array}$ & $\begin{array}{l}\text { Concrete } \\
\text { Strength } \\
\left(\mathrm{N} / \mathbf{m m}^{2}\right)\end{array}$ \\
\hline S1 & $\begin{array}{c}\text { Without } \\
\text { shear transfer } \\
\text { enhancement } \\
\text { (control) }\end{array}$ & - & - & 1.9 & 36.62 \\
\hline S2 & LYLB & $25 \times 25$ & 45 & 1.9 & 36.62 \\
\hline S3 & BTTST & $25 \times 25$ & 45 & 1.9 & 36.62 \\
\hline S4 & BTTST & $25 \times 25$ & 30 & 1.9 & 36.62 \\
\hline S5 & BTTST & $25 \times 25$ & 60 & 1.9 & 36.62 \\
\hline S6 & BTTST & $20 \times 20$ & 45 & 1.9 & 36.62 \\
\hline S7 & BTTST & $30 \times 30$ & 45 & 1.9 & 36.62 \\
\hline S8 & $\begin{array}{c}\text { Without } \\
\text { enhancement } \\
\text { (control) }\end{array}$ & - & - & 2.4 & 36.62 \\
\hline S9 & LYLB & $25 \times 25$ & 45 & 2.4 & 36.62 \\
\hline $\mathrm{S} 10$ & BTTST & $25 \times 25$ & 45 & 2.4 & 36.62 \\
\hline $\mathrm{S} 11$ & BTTST & $25 \times 25$ & 30 & 2.4 & 36.62 \\
\hline $\mathrm{S} 12$ & BTTST & $25 \times 25$ & 60 & 2.4 & 36.62 \\
\hline $\mathrm{S} 13$ & BTTST & $20 \times 20$ & 45 & 2.4 & 36.62 \\
\hline $\mathrm{S} 14$ & BTTST & $30 \times 30$ & 45 & 2.4 & 36.62 \\
\hline
\end{tabular}

\subsection{Test setup and procedures}

As shown in Figure 6, the specimen was placed vertically in the Universal Testing Machine (UTM IPC 1000). It was loaded by the $1000 \mathrm{kN}$ existing jack vertical load through a displacement-controlled method and monitored by the readings from calibrated load cells. The control speed of the displacement was set at $0.0095 \mathrm{~mm} / \mathrm{s}$. The test procedure was based on Eurocode 4 [4]. The load was applied up to $40 \%$ of the estimated failure load. The load will be cycled 25 times between $5 \%$ and $40 \%$ of the expected failure load. Testing was discontinued when the specimen failed to take the additional load or when a 
significant load drop had occurred. After the test, the specimen was dismantled to investigate the condition of the shear transfer enhancement wherever possible. The vertical slips between the slab and the cold-formed steel beam were measured by two displacement transducers (LVDT). Transducers were placed vertically at both sides of the cold-formed steel web specimen. Thin plywood with $3 \mathrm{~mm}$ thickness was placed beneath the slab and on to the upper part of the beam to level the surface. Steel plate of $30 \mathrm{~mm}$ thickness was placed on the upper plywood to receive the jack. Steel plates were fastened to the loaded end of the cold-formed steel to prevent local buckling.
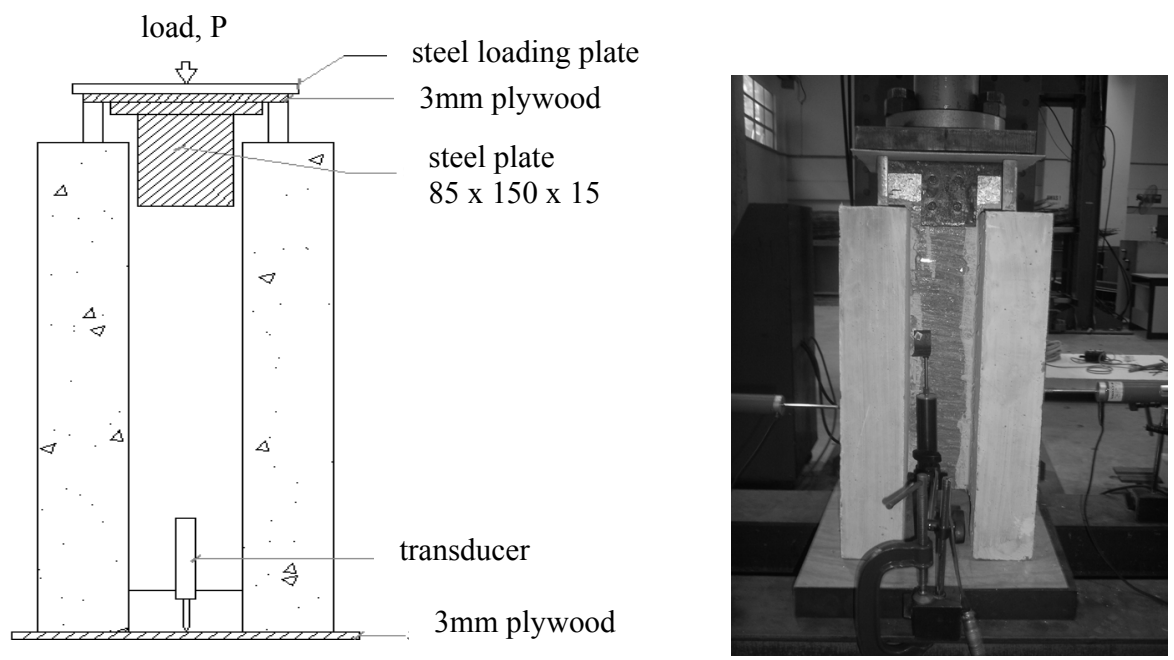

Figure 6: Push-out test arrangement.

\section{Test results and discussions}

Table 2 contains a summary of the test results at failure condition. More detailed observations of the mechanical behaviour of the tested specimens are presented in the following sections.

\subsection{Effect of the shape of shear transfer enhancements}

There will be two types of shear transfer enhancement discussed in this section named LYLB and BTTST in comparison with control specimen which no shear enhancement used and its covers both thickness of $1.9 \mathrm{~mm}$ and $2.4 \mathrm{~mm}$. The test results indicate that a significant increment of loading achieved when bent-up tap shear enhancement used in both LYLB and BTTST for both thickness $1.9 \mathrm{~mm}$ and $2.4 \mathrm{~mm}$. Referring to Figure 7, for $1.9 \mathrm{~mm}$ thick cold-formed steel section, the loading increased more than $100 \%$ for BTTST and up to $80 \%$ for LYTB as compared to the control specimens, and for $2.4 \mathrm{~mm}$ thickness, the result shows 
Table 2: $\quad$ Result of push test.

\begin{tabular}{|c|c|c|c|c|c|c|c|c|}
\hline \multirow{3}{*}{$\begin{array}{l}\text { Sp. } \\
\\
\text { S1 } \\
\end{array}$} & \multirow{3}{*}{$\begin{array}{c}\text { Ultimate } \\
\text { Load, } \\
P_{u(\text { push })} \\
(\mathrm{kN})\end{array}$} & \multicolumn{6}{|c|}{$\begin{array}{c}\text { Percentage of } \mathrm{P}_{\mathrm{u}} \text { Compared with Specimen } \\
(100 \%)-(\%)\end{array}$} & \multirow{3}{*}{$\begin{array}{c}\text { Slip, } \\
\delta_{\text {push }} \\
(\mathrm{mm})\end{array}$} \\
\hline & & \multicolumn{2}{|c|}{ Shape } & \multicolumn{2}{|c|}{ Angle } & \multicolumn{2}{|c|}{ Size } & \\
\hline & & 100 & - & - & - & - & - & \\
\hline $\mathrm{S} 2$ & 253.19 & 180 & 100 & - & - & - & - & 0.88 \\
\hline S3 & 294.65 & 210 & 116 & 124 & 100 & 156.7 & 100 & 0.91 \\
\hline $\mathrm{S} 4$ & 237.50 & - & - & 100 & - & - & - & 2.22 \\
\hline S5 & 302.41 & - & - & 127.3 & 102.6 & - & - & 0.47 \\
\hline S6 & 188.05 & - & - & - & - & 100 & - & 0.62 \\
\hline $\mathrm{S} 7$ & 307.79 & - & - & - & - & 163.7 & 104.5 & 0.57 \\
\hline S8 & 163.81 & 100 & - & - & - & - & - & 2.40 \\
\hline S9 & 289.72 & 175 & 100 & - & - & - & - & 0.95 \\
\hline $\mathrm{S} 10$ & 321.14 & 196 & 112 & 108 & 100 & 136.7 & 100 & 1.25 \\
\hline $\mathrm{S} 11$ & 297.24 & - & - & 100 & - & - & - & 2.00 \\
\hline $\mathrm{S} 12$ & 352.00 & - & - & 118.4 & 109.6 & - & - & 2.56 \\
\hline $\mathrm{S} 13$ & 234.90 & - & - & - & - & 100 & - & 0.99 \\
\hline $\mathrm{S} 14$ & 358.35 & - & - & - & - & 152.5 & 111.6 & 1.31 \\
\hline
\end{tabular}

the enhancement for LYLB and BTTST is increased up to $75 \%$ and $96 \%$ respectively. A comparison of the capacities of LYLB and BTTST indicates that the BTTST result in even higher capacities. The ultimate capacity of specimen S3 is $16 \%$ higher than that of specimen S2 and specimen S8, 12\% higher than that of specimen S7. Figure 7 also shows that the specimens with shear enhancements demonstrate significantly reduced in term of slip at the interface as compared to the control specimen. Comparing between BTTST and LYLB, better performance demonstrates at ultimate load for both thicknesses by BTTST reflecting the effect plays by the concrete at upper part and lower part of the bent-up shear tab. These comparably more desirable results can be attributed to better interlocking at the cold-formed steel-to-concrete interface.

\subsection{Effect of different BTTST angles}

The other parameter which controls the capacity of the ultimate load is the angle of the bent-up tab. Referring to Table 2, with the same angle of bent-up tab, the ultimate loading capacity of the tested specimens with $2.4 \mathrm{~mm}$ thickness is higher as compared with the specimens with $1.9 \mathrm{~mm}$ thick. Its shows that the thicker the specimen there will be an increment in the stiffness hence increased the capacity of the ultimate loading. Referring to the specimens of $60^{\circ}$ for both thicknesses, the specimen S12 gives the 16\% higher compared to the specimen S5 but more significant result shows by the specimen S11 as compared to the specimen S4 


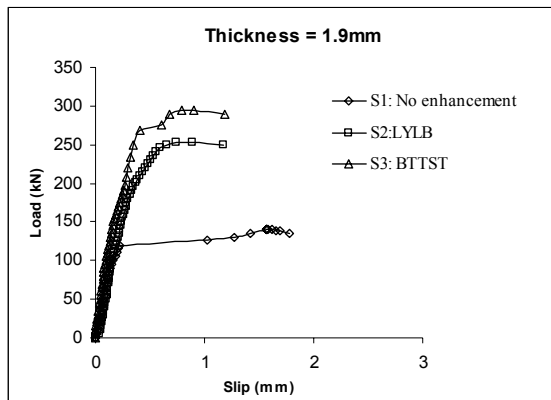

(a) $1.9 \mathrm{~mm}$ thick cold-formed steel section

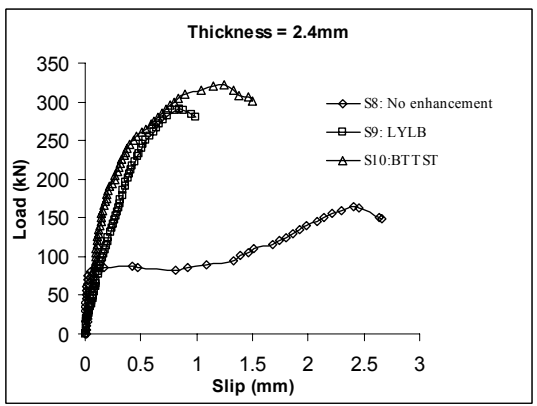

(b) $2.4 \mathrm{~mm}$ thick cold-formed steel section

Figure 7: Shear transfer enhancement comparison load-slip curves.

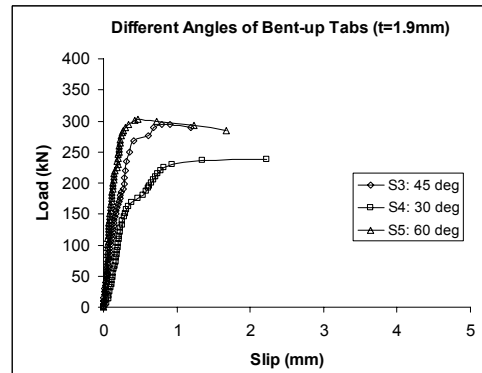

(a) $1.9 \mathrm{~mm}$ thick cold-formed steel section

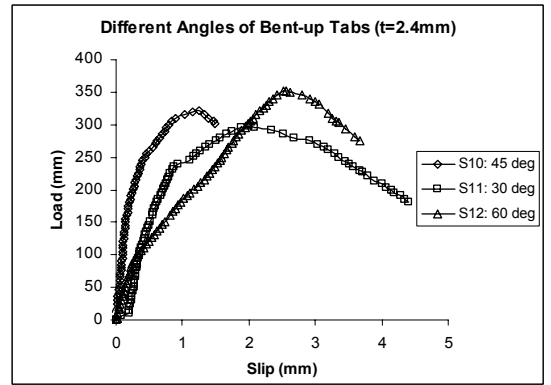

(b) $2.4 \mathrm{~mm}$ thick cold-formed steel section

Figure 8: $\quad$ Effect of the BTTST of different angles on load-slip curves.

approximately $25 \%$. Figure 8 shows the curves of the variation of ultimate load resulted from this parameter. The ultimate capacity of specimen S5 with angle $60^{\circ}$ BTTST is higher than that of specimen S3 and S4 with angle $45^{\circ}$ and $30^{\circ}$, respectively. It is $2.6 \%$ higher than specimen $\mathrm{S} 3$ and $27.3 \%$ than specimen $\mathrm{S} 4$. The ultimate capacity of specimen S3 is $24 \%$ higher than specimen S4. While from Figure $8(\mathrm{~b}), \mathrm{S} 12$ with angle $60^{\circ}$ BTTST shows a $9.6 \%$ increase in ultimate capacity over specimen S10 and $18.4 \%$ increase over specimen S11. Specimen $\mathrm{S} 10$ is higher by about $8 \%$ than specimen S11. By increase the angle of the bentup tab, the bearing area of the tab will be increased hence the ultimate load of the push out test increased. Figure 9 shows the orientation of the tab with different bent-up tab angle. For angle $45^{\circ}$ the bearing area measured was $64.6 \mathrm{~mm}^{2}$ and for angle of $60^{\circ}$ the bearing area measured was $135 \mathrm{~mm}^{2}$ increased by up to $100 \%$.

\subsection{Effect of different BTTST sizes}

Size of bent-up tab other than angle, also plays the important role to increase the bearing area hence the shear capacity of the tab. This study has been conducted 


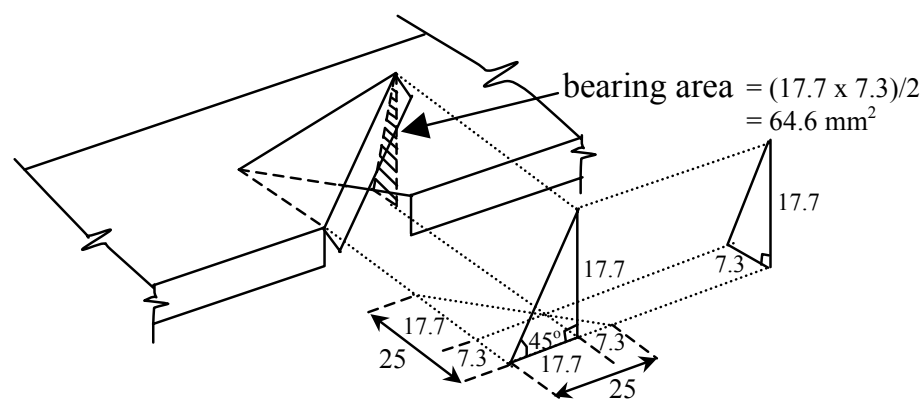

(a) Bearing area of BTTST with $45^{\circ}$ angle

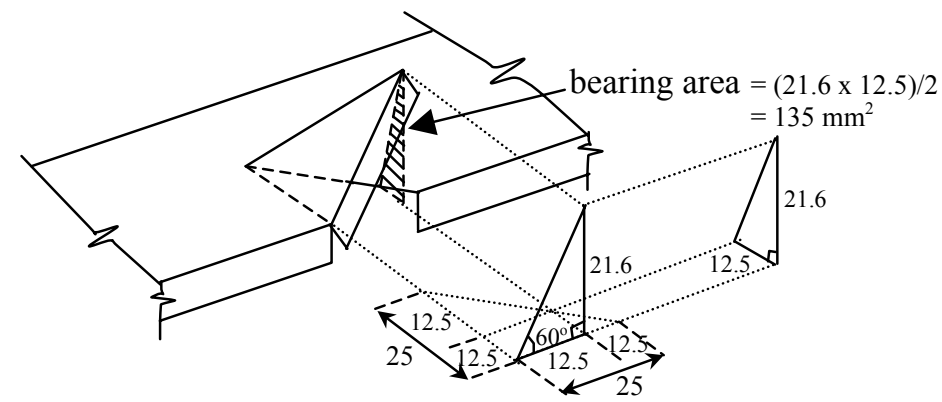

(b) Bearing area of BTTST with $60^{\circ}$ angle

Figure 9: $\quad$ Bearing area of the BTTST.

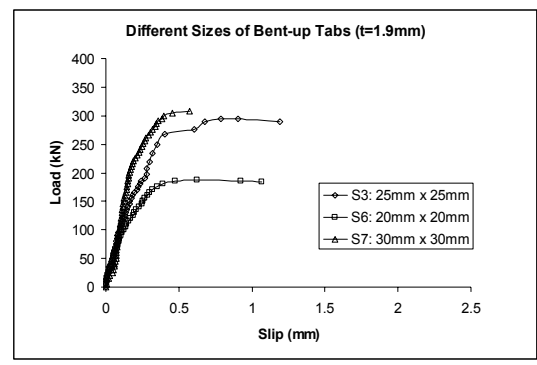

(a) $1.9 \mathrm{~mm}$ thick cold-formed steel section

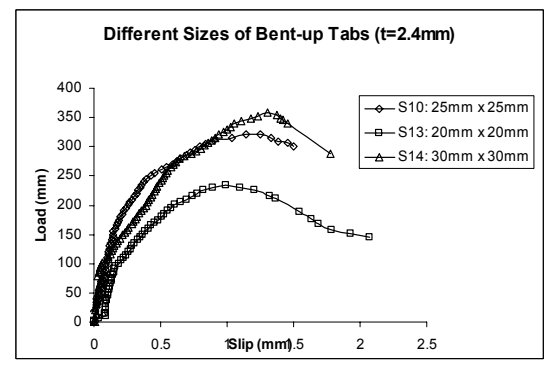

(b) $2.4 \mathrm{~mm}$ thick cold-formed steel section

Figure 10: Effects of different sizes of BTTST on load-slip curves.

on different sizes of bent-up tab shows the significant increment of the ultimate load with the increment of the bent-up tab size. For three sizes, which are $20 \mathrm{~mm} \times 20 \mathrm{~mm}, 25 \mathrm{~mm} \times 25 \mathrm{~mm}$ and $30 \mathrm{~mm} \times 30 \mathrm{~mm}$ for both thickness of $1.9 \mathrm{~mm}$ and $2.4 \mathrm{~mm}$, all specimens demonstrated the variation on their ultimate load. Referring to Figure 10, the higher area of a bent-up tab gives the higher the 
ultimate capacity of the specimen. Specimen S7 and S14, 30mmx30mm tab area increase in ultimate loading significantly as compared to the specimen S3 and S10 with the $25 \mathrm{~mm} \times 25 \mathrm{~mm}$ tab area and S6 and S13 with the $20 \mathrm{~mm} \times 20 \mathrm{~mm}$ tab area. Referring to Table 2, specimen S14 (2.4mm thick) has an increment of $16 \%$ as compared with the specimen $\mathrm{S} 7(1.9 \mathrm{~mm}$ thick) with the same shear area shows that the ultimate load was increased by increasing the thickness of the specimen. The same behaviour also showed by other tested specimens with different thicknesses. Figure 10 shows the increment of $\mathrm{P}_{\mathrm{u}}$ when the size of BTTST is increased. Increased size of BTTST would increase the bearing area. As previously discussed, the increased of bearing area tends to increase the shear resistance. This can increase the load capacity on to the cold-formed steel until the concrete achieves the ultimate load and then cracks.

\section{Conclusions}

In this paper, the problems for cold-formed steel-concrete composite beam are discussed and the enabling solution for overcome the problem are described. Previous study showed that there is very little work and lack of technical literature such as codes of practice in cold-formed steel-concrete composite beams. From this viewpoint, this research is to be carried out to study the possibility and performance of the use of a new shape of shear transfer enhancement called bent-up triangular tabs shear transfer enhancement (BTTST). BTTST enhancement was employed on the surface of the flange embedded in the concrete to provide shear transfer capacity. Fourteen companion push-out specimens were tested to evaluate the strength and behaviour of a bentup taps shear transfer enhancement. The results show that specimens employed with shear transfer enhancements increase the shear capacities of the specimens as compared to those relying only on a natural bond between cold-formed steel and concrete. As these two types of shear transfer enhancements investigated, BTTST provided the best performance in terms of strength. Shear capacities of the shear transfer enhancement also increase when angles and sizes of bent-up tabs shear transfer enhancement is increase. It is concluded that the proposed shear transfer enhancement has sufficient strength and it is feasible.

\section{Acknowledgements}

The authors would like to thank the Ministry of Higher Education, Malaysia, Universiti Tun Hussein Onn Malaysia and Universiti Teknologi MARA for sponsoring this research.

\section{References}

[1] A. Ghersi, R. Londolfo, F.M. Mazzoloni. (2002). "Design of metallic ColdFormed Thin-Walled Members". Spon Press. London. 
[2] Hanaor, A. (2000). "Test of Composite Beams With Cold-Formed Section." Journal of Constructional Steel Research 54(2): 245-264.

[3] Bhavani Shankar Lakkavalli and Yi Liu. (2006). "Experimental Study of Composite Steel C-Section Floor Joists". Journal of Constructional Steel Research. Article in press.

[4] Eurocode 4 (1994). "Design of composite steel and concrete structures: Part 1.1: General rules and rules for buildings. DD ENV 1994-1-1. Brussels”. European Committee for Standardization. 